Acta Poetica 30-1

PRIMAVERA

2009

\title{
Locuras en contrapunto: don Quijote y Enrique IV
}

\section{Cristina Múgica}

Se trata de una exploración de las representaciones de la locura en el Quijote cervantino y en el drama pirandelliano Enrique $I V$. En ambas obras, la locura es el principio activo capaz de operar el vuelco de las cosas: el principio de intercambiabilidad entre lo cómico y lo serio presente en la base del humorismo que, como lo define Pirandello, es "el sentimiento de lo contrario objetivado". En la medida en que constituye el reverso o la carnavalización de la melancolía, el andar de don Quijote es el de un actor cómico. En el caso del protagonista del drama pirandelliano, la transmutación, más que propiamente cómica, resulta sarcástica, pues se trata de una locura que responde a una fuerza destructiva — externa e interna - que finalmente llevará al protagonista a romper sus relaciones con el mundo.

Palabras Clave: Quijote, Enrique IV, locura, cómico-serio, sarcasmo.

This paper examines the depictions of folly on Quijote by Cervantes, and on the play Enrique IV by Pirandello. In both masterpieces, the folly is an active agent which interchanges comicalness and seriousness; this results in humor, which, as Pirandello states, is "the objectified sense of the opposite". Being the very antithesis or carnivalization of melancholy, don Quijote's march is the one of a comedian. As for the pirandellian character, the overturning is sarcastic instead of comical, since the protagonist's madness is a reaction to outer and inner destructive compulsions that will eventually lead him to destroy his relations to others.

Key words: Quijote, Enrique IV, folly, seriocomic, sarcasm. 

Cristina Múgica

Instituto de Investigaciones Filológicas, Universidad Nacional Autónoma de México

Locuras en contrapunto: don Quijote y Enrique IV ${ }^{1}$

En este trabajo intento examinar las representaciones de la locura en la obra maestra de Cervantes y, en tonos más sombríos, en el drama pirandelliano Enrique IV. Me parece importante decir que ambas obras se caracterizan por un principio activo capaz de operar el vuelco de las cosas: el principio de intercambiabilidad entre lo cómico y lo serio presente en la base del humorismo, que como lo define Pirandello es el "sentimiento del contrario objetivado". ${ }^{2}$ Los protagonistas de estas obras, don Quijote y Enrique IV, se representan el mundo desde la locura a partir de sus "sonadas soñadas invenciones", como se lee en la novela de Cervantes. Ahora bien, en la novela y en el drama estudiados encontramos también figuraciones de la locura

${ }^{1}$ Agradezco mucho las revisiones, observaciones y comentarios de Pilar Carrillo y Fabio Morábito.

2 Pirandello define el humorismo como el "sentimiento del contrario" (sentimento del contrario) en el ensayo "Sull'umorismo" (vid. Krysinski, El paradigma inquieto, 172-173). Cfr. Leñero: "En el tratamiento que hace Pirandello del tema de la locura se aplica también su particular concepto de humorismo, al que define como 'sutil operación' para crear el 'sentimiento de lo contrario objetivado'. Mediante la superación del sentimiento de comicidad emanado de la representación se afirma el primer y original sentimiento que tal comicidad ha mantenido oculto, explica — tal el caso del Quijote" (La luna, 55, n. 2). 
dirigidas especialmente a la mirada del loco, por ejemplo la protagonizada por la hija de la antigua amante del marqués en Enrique IV o la de Dorotea, disfrazada de la princesa Micomicona, que tiene como objetivo encaminar a don Quijote de vuelta a su aldea.

En su estudio La luna en el pozo, Carmen Leñero habla de la locura como recurso de composición de la estética pirandelliana, en particular en Enrique IV. Esta obra trata de la farsa de la locura como una forma de teatralidad, cuyo director y protagonista es el personaje principal. ${ }^{3}$ La locura en tanto recurso de composición está también presente en el Quijote, según lo plantea Aurelio González en su ensayo "La venta como teatro. Cervantes y el Quijote". González considera que en la novela cervantina la palabra del protagonista crea ámbitos de ficción, cual si se tratara de una comedia. El estudioso se refiere al episodio de la venta que a don Quijote se le "representa" como castillo, donde los personajes presentes son transformados en actores que interpretan un papel asignado. De acuerdo con este planteamiento, la locura de don Quijote habría de entenderse como una ficción teatral colectiva (110).

Para la comprensión de este trabajo comparativo entre las representaciones de la locura en el Quijote y Enrique IV, es necesario referir brevemente el argumento de ambos textos. Ante todo, considero importante hacer hincapié en la teatralidad presente en la estética del Quijote, obra que, acorde a Aurelio González, podría ser la comedia que Cervantes no escribió. En cuanto a esta obra, me limitaré a decir que trata de un hidalgo empobre-

\footnotetext{
3 "La escisión como tema a escenificar adquiere para Pirandello la forma no ya de la contradicción ni de la paradoja, sino del titubeo entre una modalidad del ser y su reverso especular. Mostrarlo así es lo que la locura — también como recurso de composición - le permite; emulándola organiza parlamentos de doble fondo, justifica acciones excluyentes, yuxtapone imágenes y trenza relatos de diversas épocas o niveles de verosimilitud. Sucede entonces que la conciencia rota y su discurso delirante desmienten con su reversibilidad la fatalidad trágica que pretende imperar en Enrique IV" (Leñero, La luna, 62).
} 
cido, ávido lector de libros de caballerías, quien un buen día, desbordado por los relatos que han pasado a poblar su fantasía, resuelve hacerse caballero andante e ir por el mundo en busca de aventuras. De esta manera, el libro narra la transformación del hidalgo en don Quijote, lo que da lugar a sucesos maravillosos a partir de los personajes que encuentra el caballero a lo largo de su camino. El final novelesco consiste en la renuncia a la locura y la recuperación de la cordura, encarnada en quien en el umbral de la muerte se llama a sí mismo Alonso Quijano.

Por ser menos conocido, es necesario presentar una síntesis más amplia del drama pirandelliano Enrique IV. Durante una mascarada en su juventud, un marqués cae del caballo y enloquece. Su locura consiste en creer que es el personaje que ha representado en la antedicha cabalgata: el emperador Enrique IV. El marqués es llevado a una villa, donde queda al cuidado de sirvientes quienes tienen la consigna de actuar como si el loco fuera efectivamente el emperador del Sacro Imperio Romano Germánico del siglo XI, acatando todos sus deseos. Pasados diez años, un día despierta curado. Decide, sin embargo, continuar representando a Enrique IV como si siguiera loco.

Veinte años después de la cabalgata, sus antiguos amigos, la marquesa Matilde Spina (de quien el protagonista estaba en secreto enamorado cuando ocurrió el accidente que lo llevó a la locura) y Tito Belcredi (actual esposo de Matilde, también participante en la anterior mascarada), acompañados de Frida, hija de Matilde, del joven marqués di Nolli, sobrino del loco, y de un médico visitan al enmascarado marqués con la intención de curarlo por medio de una escena en la que le presentarán a Matilde en contraste con su hija, quien se le parece enormemente, vestida con la misma ropa con la cual su madre había encarnado antes a la marquesa Matilde de Toscana. Con esta escena, el médico pretende que el marqués, al advertir el contraste de veinte años entre Matilde Spina y su hija, logre atravesar como de golpe los años transcurridos entre el momento de su caída y el 
presente de la diégesis. Pero la escena, lejos de curar a quien se ha enquistado en la locura, tiene por efecto fijarlo a ésta de manera definitiva, pues el protagonista, vulnerado en su delirio, reacciona y hiere a Belcredi, atravesándolo con la espada.

El delirio del personaje central del drama de Pirandello, el Gran Enmascarado, ${ }^{4}$ consiste en un guión que gira en torno a la persona de Enrique IV. Para poder entrar en contacto con esta forma de locura es necesario volverse comparsa de la misma, ya que el loco no tolera la iniciativa de otros. Así lo expresa en el primer acto de la obra un sirviente contratado para representar a uno de los jóvenes de la baja aristocracia por quienes se hacía acompañar Enrique IV:

Ladolfo: [...] nosotros, en cambio, estamos aquí, vestidos de esta manera, en esta hermosísima Corte $[\ldots]$ ¿para hacer qué? Nada... Como seis títeres colgados de la pared, que esperan que alguien los coja y los mueva de una manera o de otra y les haga decir alguna palabra (Enrique IV, I, 125). ${ }^{5}$

La locura en el caso de don Quijote consiste también en una suerte de guión que se concreta en distintas escenas, sólo que

${ }^{4}$ En su estudio La luna en el pozo, Carmen Leñero se refiere al protagonista de Enrique IV como el Gran Enmascarado, grande Mascherato en el original, que en la traducción de la cual me sirvo (Guadarrama, 1968) aparece como el Gran Disfrazado. Siguiendo a Leñero, hablaré del protagonista como el Gran Enmascarado: "Pausa lungamente tenuta. L'ombra, nella sala, comincia ad addensarsi, accrescendo quel senso di smarrimento e di piú profonda costernazione da cui quei quattro mascherati sono compressi e sempre piú allontanati dal grande Mascherato, rimasto assorto a contemplare una spaventosa miseria che non è di lui solo, ma di tutti" (Enrico IV, II, 199); "Pausa larga. Comienza a adensarse la sombra en el salón, aumentando esa sensación de confusión y de consternación que oprime a los cuatro disfrazados, los cuales están cada vez más lejos del Gran Disfrazado, que está absorto contemplando una espantosa miseria, que no es solamente de él, sino de todos" (Enrique IV, II, 184). En todas las citas de Enrique IV señalaré el acto y la página.

${ }^{5}$ Ladolfo: "Noi altri, invece, siamo qua, vestiti cosí, in questa bellissima Corte [...] - per far che? Niente [...]. Come sei pupazzi appesi al muro, che aspettano qualcuno che li prenda e che li muova cosí o cosí e faccia dir loro qualche parola" (Enrico IV, I, 132). 
en este caso no hay comparsas contratados sino, por decirlo así, voluntarios. El personaje incorpora a otros a la representación de la que es protagonista, o mejor aún, los participantes envidiosos acceden a ésta convocados, interpelados y seducidos. Así, la actuación de don Quijote, expresión de la carne enjuta de un cuerpo que se juega por completo en cada una de sus aventuras, admite otros cuerpos a pesar de la poca consideración por lo que representan fuera de su mundo.

En el primer acto de la obra Enrique IV en la villa de Umbría, acondicionada para representar el palacio imperial de Goslar, llega un grupo de personas enviado por Gregorio VII, si traducimos la visita de los amigos del marqués arriba referida a los términos delirantes de éste. El papa Gregorio VII aparece, en la historia y en la interpretación del loco, como un hechicero, gran enemigo de Enrique IV.

De tal modo, al trasponer el episodio histórico del siglo XI al presente de la diégesis se establece un paralelismo entre el emperador que vive perseguido por la excomunión de la que el papa lo ha hecho objeto y el protagonista que vive un exilio, perseguido también y atormentado. Lo anterior da cuenta de algo como una fuerza de exclusión que opera en el personaje, amenazando el transcurso de su vida. Se trata, dice Carmen Leñero, del drama de la identidad usurpada o impedida (La luna, 43). Esta vivencia del personaje pirandelliano resulta análoga a los Encantadores que persiguen a don Quijote ( $c f r$. La luna, 53) y que adquieren concreción burlesca al final de la Primera parte de la obra, cuando quienes lo acompañan en la venta lo atan de pies y manos y, encapuchados, lo meten en un carro tirado por bueyes en el que lo llevan de regreso a su aldea, tal como lo planea el cura, trazador de la escena. ${ }^{6}$

\footnotetext{
6 "Y lo que ordenaron fue que se concertaron con un carretero de bueyes que acaso acertó a pasar por allí, para que lo llevase en esta forma; hicieron una como jaula, de palos enrejados, capaz que pudiese en ella caber holgadamente don Quijote, y luego don Fernando y sus camaradas, con los criados de don Luis y los cuadrilleros,
} 
Sabemos que el personaje convertido en Enrique IV en el presente de la diégesis se exaltaba con frecuencia antes de volverse loco aunque, al decir de doña Matilde Spina, "en frío". De creerle a Belcredi:

[...] esa súbita lucidez de representación le colocaba fuera, de repente, de toda intimidad con su propio sentimiento, el cual se le aparecía — no falso, porque era sincero-, sino como algo a lo que tuviera que dar el valor... ¿cómo diría?, de un acto de inteligencia para suplir aquel calor de sinceridad cordial que notaba que le faltaba. Y entonces improvisaba, exageraba, se entregaba, para aturdirse y dejar de verse. A veces parecía inconstante, fatuo y [...] sí, digámoslo, también ridículo $(\mathrm{I}, 141)^{7}$

Por ello, la exaltación del protagonista, lejos de afirmarse en el calor del sentimiento, lo lleva al extremo de mirarse actuar una locura fingida. Y así, distanciado de su propia locura, se es-

juntamente con el ventero, todos, por orden y parecer del cura, se cubrieron los rostros y se disfrazaron, quién de una manera, y quién de otra, de modo que a don Quijote le pareciese ser otra gente de la que en aquel castillo había visto.

Hecho esto, con grandísimo silencio se entraron adonde él estaba durmiendo y descansando de las pasadas refriegas. Llegáronse a él, que libre y seguro de tal acontecimiento dormía, y asiéndole fuertemente, le ataron muy bien las manos y los pies, de modo que cuando él despertó con sobresalto no pudo menearse ni hacer otra cosa más que admirarse y suspenderse de ver delante de sí tan estraños visajes; y luego dio en la cuenta de lo que su continua y desvariada imaginación le representaba, y se creyó que todas aquellas figuras eran fantasmas de aquel encantado castillo, y que sin duda alguna ya estaba encantado, pues no se podía menear ni defender: todo a punto como había pensado que sucedería el cura, trazador desta máquina" (Don Quijote de la Mancha, I, 46, 536). Cursivas mías. En todas las citas del Quijote incluyo la parte, el capítulo y la página.

${ }^{7}$ Belcredi: “[...] quella subitanea lucidità di rapresentazione lo poneva fuori, a un tratto, d'ogni intimità col suo stesso sentimiento, che gli appariva -non finto, perché era sincero- ma come qualche cosa a cui dovesse dare lí per lí il valor [...] che so? D'un atto d'intelligenza per sopperire a aquel calore di sincerità cordiale, che si sentiva mancare. E improvvisava, esagerava, si lasciava andare, ecco, per stordirsi e non vedersi piú. Appariva incostante, fatuo e [...] sí, diciamolo, anche ridicolo, qualche volta" (I, 149). Cfr. el comentario de Leñero, La luna, 64. 
pía a sí mismo y espía a otros, agazapado tras la máscara con que se cubre, desde una distancia en la que se ha ido enfriando y vaciándose de contacto cada vez más, hasta convertirse en mera marioneta de un afán de control.

También don Quijote es capaz de exaltarse y de mirarse en su propia exaltación. Esta mirada se traduce en un incesante discurso sobre su condición de caballero andante con el que justifica y enaltece sus hazañas. En la Sierra Morena, el protagonista decide hacer una penitencia y deshacerse en quejas en una escena en la que actúa el papel del amante rechazado, "a quien una luenga ausencia y unos imaginados celos han traído a lamentarse entre estas asperezas [...]" (I, 25, 279). Consciente de que con tal representación imita a su modelo caballeresco, el protagonista hace el recuento de todos sus movimientos: "Ahora me falta rasgar las vestiduras, esparcir las armas y darme de calabazadas por estas peñas, con otras cosas deste jaez, que te han de admirar" (I, 25, 280). Además, se da tiempo para pensar en la naturaleza de su actuación y se pregunta si imitará a Roldán, "en las locuras desaforadas que hizo, o Amadís en las malencónicas” (I, 26, 290).

"El toque está en desatinar sin ocasión y dar a entender a mi dama que si en seco hago esto ¿qué hiciera en mojado?”, responde don Quijote ante la observación de Sancho en cuanto a que no hay razón para enloquecer, puesto que Dulcinea no le ha engañado. Vista así, la penitencia quijotesca constituye una parodia de la melancolía que tiene como efecto, moviendo a risa, aliviar el dolor. ${ }^{8}$

Siguiendo a Carmen Leñero, "Enrique IV se rebela ante su fatalidad fingiendo que la ha elegido. Pero el mal del que intenta escapar no es la desaparición ni la muerte: es la no existencia. Dentro de sí parasita su propia negación" (La luna, 93). Al

\footnotetext{
${ }^{8}$ Don Quijote tiene conciencia de dos de sus modelos, Amadís de Gaula y Orlando, pero se le escapa un tercero: Cardenio, "el Roto de la Mala Figura", con quien se encuentra en I, 23.
} 
caer del caballo veinte años atrás, el marqués queda fijado en la imagen del personaje que había encarnado, encantamiento que atribuye al papa hechicero: “ $i[. .$.$] no puedo separarme de esta$ obra de magia!'(Enrique IV , 159). ${ }^{9}$ Ahora bien, disipada esa ilusión diez años después, el marqués, lejos de retornar al mundo compartido, decide permanecer a cubierto en esa mascarada permanente, condenado a la repetición y, con el excedente de visión que le otorga su locura fingida, mirar a los otros mirarlo. Así, desde su melancolía reflexiva, el personaje se instala en una representación de la historia medieval, atemporal y encantado en el mundo de la imagen.

Don Quijote transforma el mundo en la medida en que incorpora a quienes lo rodean a la realidad que imagina y, de manera más importante aún, los invita a cabalgar por los territorios de su fantasía. Pero como he anotado arriba, el hacer quijotesco aparece amenazado por algo que brota de sí y que se le aparece desde el mundo externo: el encantamiento. Por su parte, acosado por el papa hechicero, Enrique IV se defiende afincándose en la villa-palacio de Goslar-Umbría, convertido a su vez en encantador.

Como Enrique IV, don Quijote queda también fijado en la imagen con la que inscribe su actuación en el teatro del mundo; desde ésta recibe golpes y agresiones, y también, de manera imaginaria, se repara y restituye. De tal suerte, en I, 43 él queda aprisionado en la broma cruel de la hija del ventero y Maritornes, quienes lo llaman a través del agujero de un pajar y le piden su mano:

A cuyas señas y voz volvió don Quijote la cabeza, y vio a la luz de la luna, que entonces estaba en toda su claridad, cómo le llamaban del agujero que a él le pareció ventana, y aun con rejas doradas, como conviene que las tengan tan ricos castillos como

${ }^{9}$ Enrico IV: “[...] non potermi piu distaccare da quest'opera di magia!” (Enrico $I V$, II, 170). 
él se imaginaba que era aquella venta; y luego en el instante se le representó en su loca imaginación que otra vez, como la pasada, la doncella fermosa, hija de la señora de aquel castillo, vencida de su amor tornaba a solicitarle, y con este pensamiento, por no mostrarse descortés y desagradecido, volvió las riendas a Rocinante y se llegó al agujero (I, 43, 506).

Don Quijote les tiende la mano, respondiendo a su solicitud ("para que miréis la contextura de sus nervios, la trabazón de sus músculos, la anchura de espaciosidad de sus venas") y Maritornes,

[...] haciendo una lazada corrediza al cabestro, se la echó a la muñeca y, bajándose del agujero, ató lo que quedaba al cerrojo de la puerta del pajar, muy fuertemente (I, 43, 508).

Las mozas lo dejan colgando de la mano durante toda la noche, situación que el caballero atribuye a un encantamiento: dolorosa suspensión de su cuerpo por parte de un poderoso hechicero.

En su delirio, don Quijote recurre al encantador y al encantamiento toda vez que se ve confrontado con la realidad, como ocurre en la aventura de los molinos de viento o en la de los ejércitos que resultan ser carneros. ${ }^{10}$ La siguiente explicación

10 "Calla, amigo Sancho — respondió don Quijote-, que las cosas de la guerra más que otras están sujetas a continua mudanza; cuanto más, que yo pienso, y es así verdad, que aquel sabio Frestón que me robó el aposento y los libros ha vuelto estos gigantes en molinos, por quitarme la gloria de su vencimiento: tal es la enemistad que me tiene; mas al cabo al cabo han de poder poco sus malas artes contra la bondad de mi espada" (I, 8, 96).

En el episodio de los rebaños: “- Como eso puede desaparecer y contrahacer aquel ladrón del sabio mil enemigos. Sábete, Sancho, que es muy fácil cosa a los tales hacernos parecer lo que quieren, y este maligno que me persigue, envidioso de la gloria que vio que yo había de alcanzar desta batalla, ha vuelto los escuadrones de enemigos en manadas de ovejas. Si no haz una cosa, Sancho, por mi vida, porque te desengañes y veas ser verdad lo que te digo: sube en tu asno y síguelos bonitamente y verás cómo en alejándose de aquí algún poco, se vuelven en su ser primero 
dirigida a Sancho a propósito de la aventura del yelmo de Mambrino da cuenta de la perspectiva quijotesca en lo tocante a la relación del mundo de la fantasía con el de la realidad:

¿Qué es posible que en cuanto ha que andas conmigo no has echado de ver que todas las cosas de los caballeros andantes parecen quimeras, necedades y desatinos, y que son todas hechas al revés? Y no porque sea ello ansí, sino porque andan entre nosotros siempre una caterva de encantadores que todas nuestras cosas mudan y truecan, y las vuelven según su gusto y según tiene la fama de favorecernos y destruirnos; y así, eso que a ti te parece bacía de barbero me parece a mí el yelmo de Mambrino y a otro le parecerá otra cosa (I, 25, 277).

En una tesitura muy distinta de la del festivo razonamiento quijotesco arriba referido, "fuera del mundo, fuera del tiempo, fuera de la vida", el loco pirandelliano saluda con una mueca terrorífica; confrontarse con éste "es encontrarse delante de uno que te derriba hasta los cimientos todo cuanto habéis construido en vosotros, la lógica de todas vuestras construcciones" (Enrique IV, II, 183). ${ }^{11}$ Los locos, dice Enrique IV, "costruiscono senza logica" (II, 198), "construyen sin lógica” [...] “ $; \mathrm{O}$ con una lógica suya que vuela como una pluma!" (II, 183). ${ }^{12}$

El mundo de apariencia en el que vive está para Enrique IV poblado de fantasmas que, desbordando el soterrado mundo de la psique, permea la realidad, "imágenes que no conseguimos mantener en el reino del sueño" (II, 178). ${ }^{13}$ Es esto lo que percibe el personaje que, desde una locura fingida, suerte de

y, dejando de ser carneros, son hombres hechos y derechos como yo te los pinté primero. Pero no vayas agora, que he menester tu favor y ayuda: llégate a mí y mira cuántas muelas y dientes me faltan, que me parece que no me ha quedado ninguno en la boca" (I, 18, 195).

11 "[...] trovarsi davanti a uno che vi scrolla dalle fondamenta tutto quanto avete construito in voi, attorno a voi, la logica, la logica di tutte le vostre construzioni" (Enrico IV, II, 198).

12 "O con loro logica che vola come una piuma!" (Enrico IV, II, 198).

13 "[...] immagini che non si riesce a contenere nei regni del sonno" (II, 192). 
reflexión delirante, es capaz de descubrir los mecanismos por medio de los cuales se le impone la mirada y el juicio de los otros:

Enrique IV: Pero decidme: ¿se puede permanecer tranquilo pensando que hay alguien que se afana en persuadir a los demás de que sois como él os ve, en fijaros en la estimación de los demás según el juicio que él ha hecho de vosotros? (II, 180). ${ }^{14}$

Desde su marginación, el loco descubre las imposiciones de que son objeto los grupos subalternos por parte de los grupos dominantes:

Enrique IV: (a sus acompañantes) [...] Vosotros también tenéis el vuestro (modo de pensar) ¿no? ¡Claro! Pero ¿cuál puede ser el vuestro? ¡El del rebaño! Miserable, lábil, incierta... Y aquéllos se aprovechan, os hacen soportar y aceptar su manera, para que sintáis, y veáis como ellos (II, 180-181). ${ }^{15}$

Ahora bien, mientras los grupos subalternos son sometidos a una visión de la realidad impuesta, mirada y juicio sobre sí mismos y el mundo que legitiman en la medida en que la reflejan, fuera del laberinto del reflejo, el rey y el loco se tocan, ya que ambas condiciones implican soberanía:

Enrique IV: ¡Os ordeno que os arrodilléis, todos delante de mí! ¡Así! ¡Y tocad tres veces el suelo con la frente! ¡Vamos! ¡Delante de los locos, todo el mundo tiene que estar así! (II, 181). ${ }^{16}$

${ }^{14}$ Enrico IV: "Ma dite un po', si può star quieti a pensare che c'è uno che si affanna a persuadere agli altri che voi siete come vi vede lui, a fissarvi nella stima degli altri secondo il giudizio che ha fatto di voi?" (II, 194).

${ }^{15}$ Enrico IV: "Avete anche voi il vostro, eh? Certo! Ma che può essere il vostro? Quello della mandra! Misero, labile, incerto [...] E quelli ne approfitano, vi fanno subire e accettare il loro, per modo che voi sentiate e vediate come loro! " (II, 194).

${ }^{16}$ Enrico IV: "Vi ordino di inginoccharvi tutti davanti a me -cosí! E toccate tre volte la terra con la fronte! Giù tutti, davanti ai pazzi, si debe stare cosí!" (II, 195). 
Convencido de que como caballero andante ha entregado su vida a la causa de la justicia, don Quijote siente como legítima la voluntad soberana de sus actos. De esta manera, cuando la policía de caminos irrumpe en la venta en la que se aloja con la intención de aprehenderlo por haber libertado a los galeotes, protesta:

Venid acá, ladrones en cuadrilla, que no cuadrilleros, salteadores de caminos con licencia de la Santa Hermandad, decidme: ¿quién fue el ignorante que firmó mandamiento de prisión contra un tal caballero como yo soy? ¿Quién el que ignoró que son esentos de todo judicial fuero los caballeros andantes y que su ley es su espada, sus fueros sus bríos, sus premáticas su voluntad? ¿Quién fue el mentecato, vuelvo a decir, que no sabe que no hay secutoria de hidalgo con tantas preeminencias ni esenciones como la que adquiere un caballero andante el día que se arma caballero y se entrega al duro ejercicio de la caballería ¿Qué caballero andante pagó pecho, alcabala, chapín de la reina, moneda forera, portazgo ni barca? ¿Qué sastre le llevó hechura de vestido que le hiciese? ¿Qué castellano le acogió en su castillo que le hiciese pagar el escorte? ¿Qué rey no le asentó a su mesa? ¿Qué doncella no se le aficionó y se le entregó rendida a todo su talante y voluntad? Y, finalmente, ¿qué caballero andante ha habido, hay ni habrá en el mundo que no tenga bríos para dar él solo cuatrocientos palos a cuatrocientos cuadrilleros que se le pongan delante? (I, 45, 529).

Perdido el registro de sí mismo, Enrique IV cree en lo que para otros pertenece al reino de la apariencia. ${ }^{17} \mathrm{El}$ personaje se siente incapaz de soportar un cruce de miradas o de reconocerse en los ojos del ser amado ante cuya frontera vigilante se sitúa "como un mendigo ante una puerta":

17 "La luna nel pozzo" (II, 199) es la imagen pirandelliana en torno a la cual está tejido el libro de ensayos homónimo de Carmen Leñero. 
Enrique IV: ; [...] el que entra por ella, nunca seréis vosotros, con vuestro mundo dentro, como lo veis y lo tocáis, sino un desconocido para vosotros, tal como el otro, en su mundo impenetrable, os ve y os toca! (II, 184). ${ }^{18}$

La caída del caballo de Enrique IV constituye una metáfora del afecto caído. ${ }^{19}$ El delirio brota después de la catástrofe a la que se refiere Freud como "sepultamiento del mundo", esto es, como un intento de reconstruir el mundo perdido. ${ }^{20}$ De este modo, el personaje pierde su cuerpo y queda fijado a la imagen del soberano excomulgado.

Por su parte, en su delirio, don Quijote se siente llamado a actuar el deseo del hidalgo. Y si este último aparece inmovilizado, caído, avasallado, don Quijote se yergue en afán de conquista y fama. Ahora bien, la locura quijotesca se produce desestabilizando el mundo en que se inscribe, trastocando significaciones, carnavalizando, para tener ahí cabida. El andar del caballero es el de un actor cómico, revelador de la permanente escisión entre lo que el hombre cree ser y hacer y su transcurso ante la mirada de los otros, que se expresa en la risa.

Regreso a la obra pirandelliana. Veinte años después de acaecida la locura en el personaje, el Enmascarado recibe el eco de la voz de su amada (la voz de Frida interpretando a su madre, Matilde) como si fuera "una cuchillada a traición en la espalda" (Enrique IV, III, 189). ${ }^{21} \mathrm{El}$ mismo impacto, la misma humilla-

${ }^{18}$ Enrico IV: "[...] chi vi entra, non sarete mai voi, col vostro mondo dentro, come lo vedete e lo toccate; ma uno ignoto a voi, come quell'altro nel suo mondo impenetrabile vi vede e vi tocca [...]" (Enrico IV, 199).

${ }^{19}$ Siguiendo a Freud, esta caída constituye el primer momento de la locura, cuando el enfermo sustrae de las personas de su entorno y del mundo exterior la investidura libidinal, catástrofe que se proyecta como el sepultamiento del mundo.

20 "Con relación a las génesis de las formaciones delirantes, algunos análisis nos han enseñado que el delirio se presenta como un parche colocado en el lugar donde originariamente se produjo una desgarradura en el vínculo del yo con el mundo exterior" (Freud, "Neurosis y psicosis", 157).

21 "colpito a tradimento da una rasojata alla schiena [...]" (Enrico IV, II, 205). 
ción que lo había precipitado hacia a la locura, sólo que, en el presente de la diégesis, en lugar de arrancarlo de la realidad desgarra el mundo en el que se protege como una ráfaga inesperada. Pero tal como apunté arriba, la recuperación de la cordura había sido antes:

Enrique IV: [...] Abro los ojos poco a poco y a lo primero no sé si estoy dormido o despierto; sí, estoy despierto; toco una cosa, después otra; vuelvo a ver claramente [...] (III, 195). ${ }^{22}$

Consciente de su lucidez, el personaje decide sin embargo reservársela para servirse del excedente de visión de la locura fingida como arma defensiva en contra de la burla, el escarnio, la traición: la herida: ${ }^{23}$

Enrique IV: ¡Vivir, con la más lúcida conciencia, mi locura y vengarme así de la brutalidad de una piedra que me había machacado la cabeza! (III, 196). ${ }^{24}$

La locura se convierte en una forma de suplir la soledad y de evadir el tiempo pasado y no vivido ${ }^{25}$ constituye, asimismo, la

${ }^{22}$ Enrico IV: "Riapro gli occhi a poco a poco, e non so in prima se sia sonno o veglia; ma sí, sono sveglio; tocco questa cosa e quella; torno a vedere chiaramente" (II, 212).

${ }^{23}$ Enrique IV: "Y no ver ya nada, mi querido amigo, de todo lo que después de aquel día de carnaval ocurrió, para vosotros y no para mí; cómo cambiaron las cosas; cómo me traicionaron los amigos; el lugar que otros ocuparon, por ejemplo [...] ¡qué sé yo!, pero supón que en el corazón de la mujer que uno amaba [...]" (III, 194); Enrico IV: "E non vedere piú nulla, caro, di tutto ciò che dopo quel giorno di carnevale avvenne, per voi e non per me; le cose, come si mutarono; gli amici, come mi tradirono; il posto presto da altri, per esempio...che so! Ma supponi nel cuore della donna che tu amavi [...]" (III, 211).

${ }^{24}$ Enrico IV: "Viverla — con la piú lucida coscienza - la mia pazzia e vendicarmi cosí della brutalitá d'un sasso che m'aveva ammaccato la testa!” (III, 214).

${ }^{25}$ Enrique IV: "[...] yo llegaría con un hambre de lobo a un banquete terminado hacía ya bastante tiempo" (III, 196); Enrico IV: "[...] e che sarei arrivato con una fame da lupo a un banchetto già bell'e sparecchiato" (III, 213). 
verdad de lo que escapa a la razón e inevitablemente se fuga de ésta. ${ }^{26}$ "La locura aparece entonces como un estado de lucidez frente a la verdadera condición existencial de todos, como un gesto de iluminación en medio del oscuro desconocimiento de sî" (Leñero, La luna, 68):

Enrique IV: Estoy curado, señores, porque sé perfectamente que hago el loco, y lo hago tranquilo. Lo malo es que vosotros vivís vuestra locura agitadamente, sin verla y sin saberla (III, 198). ${ }^{27}$

Fijado en la eternidad de la máscara ("Fisso in questa eternità di maschera!” [III, 199]), la incisión que produce la súbita irrupción de la hija de Matilde en el delirio del personaje, en vez de devolver al mundo a este último, le provoca un arrebato de rabia y de venganza que culmina en un gesto reflejo en el que, herido por el otro, lo herirá a su vez: “¿Es un famoso espadachín? Me atravesará" (II, 187). ${ }^{28}$

De esta manera, la carne que atraviesa la espada del Enmascarado, lejos de romper el hechizo, termina por desligar su cuerpo del reflejo; la locura propia de la de los otros; excluido del mundo y condenado, esta vez por voluntad propia. ${ }^{29}$

${ }^{26}$ Enrique IV: "Esto, esto que para mí es la caricatura, evidente y voluntaria, de esa otra mascarada, continua, de cada minuto, de la que somos payasos involuntarios cuando sin saberlo nos disfrazamos de lo que nos parece que somos [...]" (III, 197); Enrico IV: "Questo, questo che è per me la caricatura, evidente e volontaria, di quest'altra mascherata, continua, d'ogni minuto, di cui siamo i pagliacci involuntarii quando senza saperlo ci maschaeriamo di ciò che ci par d'essere [...]" (III, 215).

${ }^{27}$ Enrico IV: "Sono guarito, signori: perché so perfettamente di fare il pazzo, qua; e lo faccio, quieto! - Il guajo è per voi che la vivete agitatamente, senza vederla la vostra pazzia" (III, 216).

28 "È un famoso spadaccino? M'infilzerà [...]" (II, 203).

29 “[...] porque Enrique IV soy yo: yo aquí, desde hace veinte años, ¿entiende? ¡Fijado en esta eternidad de máscara!” (I, 199); “[...] perché Enrico IV sono io: io, qua, da venti anni, capite? Fisso in questa eternetà di maschera!” (III, 217). 


\section{A manera de conclusión}

En su obra Mentira romántica y verdad novelesca, René Girard explica la locura quijotesca como una forma de "deseo metafísico" que implica la ficcionalización de la realidad del personaje cuyo deseo mimetiza el de otro. Ahora bien, de acuerdo con este autor, don Quijote, el más sereno de los héroes de la mímesis, se somete de manera explícita al deseo de su modelo. El final novelesco de la obra consiste, siguiendo a Girard, en el descubrimiento de la impostura de la ficción y en el regreso del personaje a su mundo, simbolizado en el nombre de Alonso Quijano. Desde esta perspectiva, la enfermedad "metafísica" en el Enrique $I V$ resulta más grave y en cierto modo contraria a la de don Quijote, ya que si este último surge como una suerte de instancia carnavalesca del interior del protagonista, el marqués se ve por el contrario sofocado por una máscara firmemente adherida al rostro. La enfermedad del segundo personaje se complica cuando, recuperada la lucidez, decide adoptar la máscara como impostura, con lo que, a fuerza de falsificarse, termina por anular su relación con el mundo.

Así, mientras don Quijote cabalga por el mundo transformándolo con su locura, Enrique IV permanece fijado en la máscara del soberano excomulgado en una suerte de umbral, una zona de protección desde la cual ejercer control sobre los otros, siempre sujeto a su lucidez desolada, tanto en su locura auténtica como en la fingida.

En las dos obras analizadas, la locura es el principio que opera la intercambiabilidad entre lo cómico y lo serio, en la medida en que constituye el reverso carnavalesco de la melancolía. Por ello, a pesar de sus perseguidores, don Quijote es capaz de transmutar los molinos de viento en gigantes, carneros en ejércitos y una bacía en el yelmo de Mambrino, y de construir un mundo al revés. Para justificar su delirio elabora sus argumentos ante las cosas, tal como resultan para los otros y para sí mis- 
mo después de su actuación alucinada. El personaje cervantino encarna la angustia ante la amenaza de ser desposeído de la vida misma. En su intento por escapar inunda el mundo con el sentimiento de su cuerpo.

En el caso del drama pirandelliano, el principio de transmutación, más que propiamente cómico, resulta sarcástico, pues se trata de una locura que se desdobla proveniente de una fuerza destructiva que llevará finalmente al personaje a atentar contra sus relaciones con el mundo. En algún momento de melancolía reflexiva, el protagonista tiene la posibilidad de regresar a su mundo, pero ante la intervención del médico y sus amigos, Enrique IV se repliega. Víctima de la traición, al intentar denunciarla adopta sus mecanismos; encantador, entonces, opera un mundo de sombras; es capaz desde su noche de sembrar la muerte.

\section{REFERENCIAS}

Cervantes, Miguel de, Don Quijote de la Mancha, Edición del Instituto Cervantes dirigida por Francisco Rico. Barcelona, Instituto Cervantes, Crítica, 1998.

FReUd, Sigmund, "Neurosis y psicosis" [1924], en Obras completas XIX, ordenamiento, comentarios y notas de James Strachey con la colaboración de Anna Freud, trad. José L. Etcheverry, Buenos Aires, Amorrortu.

__, "La pérdida de realidad en la neurosis y la psicosis" [1924], en Obras completas XIX, ordenamiento, comentarios y notas de James Strachey con la colaboración de Anna Freud, trad. José L. Etcheverry, Buenos Aires, Amorrortu.

GIRARD, René, Mentira romántica y verdad novelesca, Barcelona, Anagrama, 1985.

GonzÁlez, Aurelio, "La venta como teatro. Cervantes y el Quijote", en El "Quijote" desde América, Gustavo Illades y James Iffland (eds.), México, Benemérita Universidad Autónoma de Puebla, El Colegio de México, 2006, 101-117. 
Krysinski, Wladimir, El paradigma inquieto. Pirandello y el campo de la modernidad (2005), trad. Alfonso de Toro en colab. con Milena Grass, Madrid, Vervuert Verlag, Iberoamericana, 1995 (Teoría y práctica del teatro, 4).

LeÑERo, Carmen, La luna en el pozo, México, Conaculta, 2000 (Sello Bermejo).

Múgica Rodríguez, Cristina, Ensayos en torno a la locura de don Quijote, México, Universidad Nacional Autónoma de México, 2005 (Cuadernos del Seminario de Poética, 23).

PIRANDEllo, Luigi, Sei personaggi in cerca d'autore-Enrico IV [1948], Italia, Arnoldo Mondadori Editore, 1975.

—-, Teatro, Madrid, Ediciones Guadarrama, 1968.

Rossi, Annunziata, "La visión trágica de la vida en la obra de Luigi Pirandello", Acta Poetica 25-1, 2004, 257-278. 